\title{
Comparative Analysis of Emitted Magnetic Fields from Liquid Crystal Display (LCD) and Light Emitting Diode (LED) System
}

\author{
B. I. Bakare, Victor T. Taol and Sunny Orike
}

\begin{abstract}
This paper present the Comparative analysis of emitted magnetic fields from Liquid Crystal Display(LCD) and that of Light Emitting Diode (LED) system . A total of eighteen Liquid Crystal Display and Light Emitting Diode monitors from different manufacturers were used. The magnetic field was measured using a trifield guass meter. The trifield guass meter was placed perpendicularly to the monitors at $5 \mathrm{~cm}$ steps from the monitor up to $70 \mathrm{~cm}$ and the magnetic field from each monitor was recorded in milligauss. The result showed that the magnetic field of the liquid crystal display monitors is almost 2 times greater than that of the light emitting diode monitors. The obtained results was compared with international occupational and general public recommended exposure limit and The result was found to be below the permissible dose limit according to the IEEE( Institute of Electrical and Electronics Engineering) standard. Altough there is minimal evidence of the health risk associated to the use of Visual Display Units (VDUs) and it is inconclusive.
\end{abstract}

Index Terms-Magnetic field; Computers; Systems; Monitor.

\section{INTRODUCTION}

The use of computers has become almost inevitable throughout the world and very common in all sphere of life. However, the users usually encounter some electric and magnetic field from the systems. In the same way electric and electronic devices such as transmission lines, transmission lines, television and radio, mobile communication systems, as well as domestic electrical appliances are also sources of included electric and magnetic [1].

One of the main characteristics that define an electromagnetic field (EMF) is its frequency or its corresponding wavelength. Fields of different frequencies interact with the body in different ways. One can imagine electromagnetic waves as series of very regular waves that travel at an enormous speed, the speed of light. The frequency simply describes the number of oscillations or cycles per second, while the term wavelength describes the distance between one wave and the next. Hence wavelength and frequency are inseparably intertwined: the higher the frequency the shorter the wavelength. [2]

In many homes, offices, classrooms, laboratories and industries computer users spend long periods of time working on the system.Several industries have been made to ascertain whether health is linked with utilization of computer systems especially with the monitors. The studies are still inconclusive about the true situation of the matter. In light of the above, the comparison of magnetic fields from Liquid Crystal Display (LCD) and Light Emitting Diode (LED) was carried out. It should be pointed out that the induced electric fields are very low and are not measurable

Computer and its mechanism are referred as hardware. Computer hardware include the memory that saves information and program instruction; the central processing unit (CPU) that pass out program commands; the input gadgets, like the keyboard or mouse, that permit the client to converse with the computer; the output gadget, such as printers and video display terminal (monitor), which let the computer to bring out information to the client as shown in figure 1 below. The programs which make the computer work are known as software. Software normally is intended to carry out a particular job and direct the all-purpose process of the computer. The Central processing unit and monitor communication involves current move therefore bring into being magnetic field."
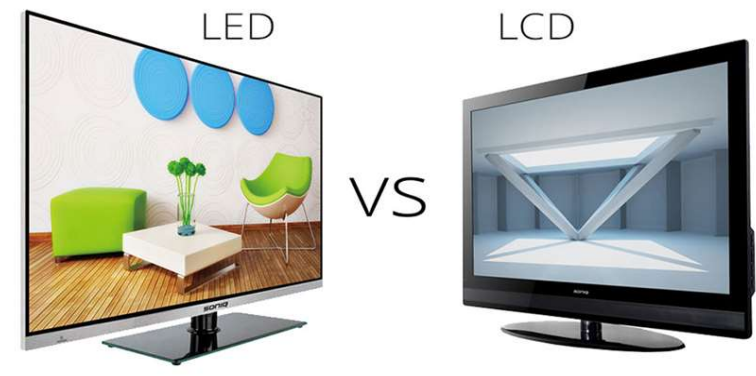

Fig. 1. Display Terminal (Monitors)

"There are breaches in the systematic understanding of the effects of EMFs, and most study is at present ongoing to amplify that awareness. research have been, and are being, conducted by the Institute of Electrical and Electronics Engineers (IEEE), United Nations World Health Organization (WHO), United States Environmental Protection Agency (EPA), United States Department of Energy (DOE) and many other organizations. The International Radiation Protection Association (IRPA) has

B. I Bakare is with the Electrical Engineering Department, Rivers State University, Port Harcourt. Nigeria.

(e-mail: bakare.budurin@ust.edu.ng)

Victor T. Taol is with the Electrical Engineering Department, Rivers State University, Port Harcourt. Nigeria.

Sunny Orike is with the Computer Engineering Department, Rivers State University, Port Harcourt. Nigeria. 
chartered a committee called the International Non-Ionizing Radiation Committee (INIRC) to study the issue of EMFs. This committee is a scientific advisory group whose members have extensive expertise with non-ionizing radiations like microwaves and EMFs. They have published guidelines on limits of exposure to $50 / 60 \mathrm{~Hz}$ electric and magnetic fields. This suggestion well thought-out all the available systematic information. The suggestion state that "members of the general public should not be exposed on a continuous basis to electric field strengths exceeding $5 \mathrm{kV} / \mathrm{m}$," or to magnetic fields exceeding $0.1 \mathrm{mT}$ ( 1 gauss or $1,000 \mathrm{mG}$ ). Electrical workers, such as usefulness linemen or electrical service workers, should not be exposed to electric fields larger than $10 \mathrm{kV} / \mathrm{m}$ except for small periods of time. Magnetic fields for work-related exposure should be partial to fewer than $0.5 \mathrm{mT}$ (5 gauss or $5,000 \mathrm{mG})$."

Several works have been done on magnetic field from CRT (Cathode Ray Tube) and LCD (Liquid Crystal Display) monitors. These works have made progress over the years, but the CRT monitors have gone obsolete and there is need to measure the magnetic field from LED (Light Emitting Diode) and compare it to LCD. This work seeks to compare the magnetic field from LCD and LED.

\section{LIGHT EMITTING DIODE (LED) AND LIQUID CRYSTAL DISPLAY (LCD)}

\section{A. Light Emitting Diode}

An LED computer (Light Emitting Diode) is a plane monitor, flat panel computer monitor or television. It comes with an extremely small depth and is not heavy in terms of mass. The real dissimilarity amid the LED and a characteristic LCD computer is the backlighting. The initial LCD monitors had CCFL (Cold Cathode Flourescent lamp) in its place of LEDs to light up the monitors

\section{B. Liquid Crystal Display}

Liquid Crystal Display screens. As the name implies, apply liquid crystal display technology, which makes it more dissimilar from the normal Cathode Ray Tube monitors [3]and[4]. A Liquid Crystal Display is a slim and smooth exhibit gadget comprising of pixels arrayed in frontage of a light supply of reflector.

\section{MATERIALS AND METHOD}

\section{A. Materials}

The basic material used for this research is Trifield Gauss Metre shown in figure 2 below. The typical unit of magnetic field power is called the tesla (T). the Tesla is a very big unit, so calculated magnetic fields are often only a small number of millionths of a tesla, called a microtesla $(\mu \mathrm{T})$.An older, non-standard unit of magnetic field is the gauss $(\mathrm{G})$.

10,000 gauss $=1$ tesla. The magnetic field or fluxes were measured using a trifield gauss metre. The magnetic field more accurately refers to magnetic flux density and is reported in the units of milligauss $(\mathrm{mG})$ and microtesla $[\boldsymbol{\mu T}]$
1 microtesla $[\mu T] 10$ milligauss $[m G]$

10,000 Gauss $=1$ Tesla

Magnetic Field Magnitude $=$

(permeability of free space) (current magnitude)

$$
B=\frac{\mu_{0} I}{2 \pi r}
$$

Where

$\mathrm{B}=$ magnetic field magnitude (Tesla, $\mathrm{T})$

$\mu_{0}=$ permeability of free space $\left(4 \pi \times 10^{-7} \mathrm{~T} \mathrm{~m} / \mathrm{A}\right)$

$\mathrm{I}=$ magnitude of the electric current (Amperes, A)

$\mathrm{r}=\operatorname{distance}(\mathrm{m})$

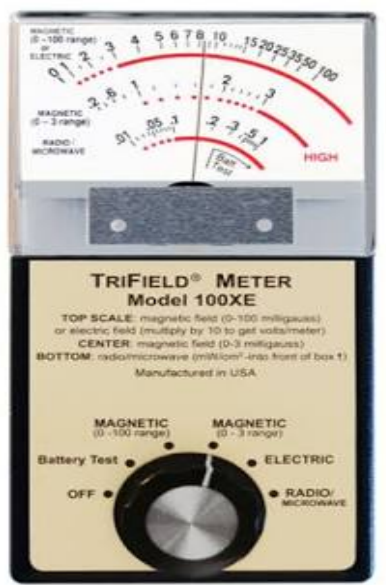

Fig. 2. Trifield Gauss Metre

\section{B $\quad$ Method}

Firstly, the residual magnetic fields within the laboratory was measured and recorded as:

Residual Magnetic Field $=0.0$ Milligauss $[\mathrm{mG}]$.

After which the computer was turned on and allowed to stay on for five (5) minutes for equilibrium before measurement. Residual magnetic field is the induced magnetic field as a result of other electrical appliances that probably can produce magnetic flux installed in the laboratory.

All the measurements were taken at the direction perpendicular to the screen. The investigations was performed by placing the Trifield Gauss metre before the monitor screen in the middle. The distance will be varied at $5.0 \mathrm{~cm}$ interval up to $70 \mathrm{~cm}$ from the front of the screen. At each point, the flux will be measured and recorded against that distance. This was done by measuring magnetic flux in front of the monitors using a Trifield gauss metre.as shown in figure 3 below. This will be repeated for all the computer monitors used for this study

$$
\begin{aligned}
& 1 \text { Tesla }=1 . \times 10^{7} \text { Milligauss }[\mathrm{mG}] \\
& 1 \text { Tesla }=1 . \times 10^{6} \text { Microtesla }[\mu T]
\end{aligned}
$$




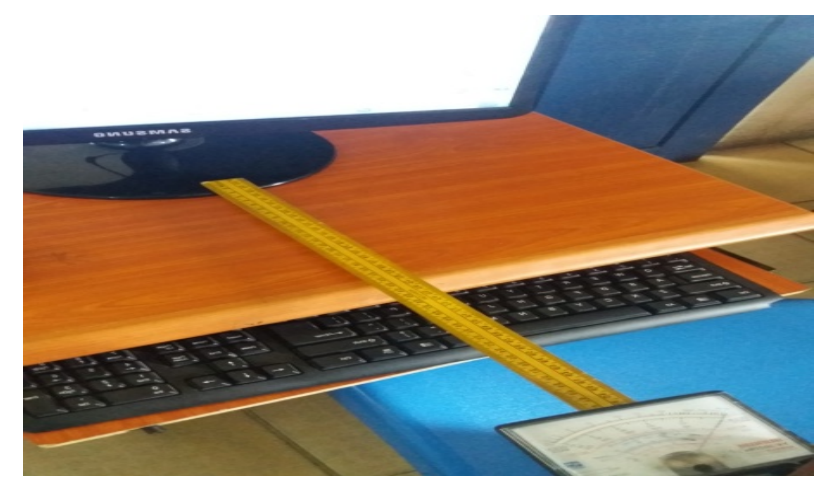

Fig. 3. Measurement of Magnetic Field using Trifield Gauss Metre

The measurement was carried out on eighteen (18) computer monitors nine (9) of which are LCD monitors of different size, power rating and manufacturers. The remaining nine (9) are LED monitors. These LCD monitors was used for comparison. The measurements will be carried out within the ITC unit at Rivers State University of Science and Technology and computer laboratory of Betty Ivory Towers Port Harcourt.

At each point, the flux will be measured and recorded against that distance, tabulated as shown in the tables below

\section{Presentation of Data}

The table consist of numeric values of magnetic field from 14", 17" and 21" LCD and LED monitors of three different products namely System A, System B and System C. From the measurement, at distances $5 \mathrm{~cm}-70 \mathrm{~cm}(5 \mathrm{~cm}$ interval) the magnetic field for the three different systems were recorded and summarized as shown below

1. This table consist of numeric values of magnetic field from 14" LCD monitors of three different products namely System A, System B and System C.

\begin{tabular}{|c|c|c|c|}
\hline $\begin{array}{c}\text { DISTANCE } \\
\text { FROM THE } \\
\text { SCREEN } \\
(\mathrm{CM})\end{array}$ & $\begin{array}{l}\text { SYSTEM A } \\
\text { (50/60Hz: } \\
1.4 \mathrm{~A}) \\
\text { (MILLI- } \\
\text { GAUSS) } \\
\end{array}$ & $\begin{array}{l}\text { SYSTEM B } \\
\text { (50/60Hz: } \\
\text { 1.4A) (MILLI- } \\
\text { GAUSS) }\end{array}$ & $\begin{array}{l}\text { SYSTEM C } \\
(50 / 60 \mathrm{~Hz}: \\
1.4 \mathrm{~A}) \\
\text { (MILLI- } \\
\text { GAUSS) } \\
\end{array}$ \\
\hline 5.00 & 26.00 & 30.00 & 35.00 \\
\hline 10.00 & 25.00 & 27.00 & 34.00 \\
\hline 15.00 & 20.00 & 24.00 & 30.00 \\
\hline 20.00 & 13.80 & 22.00 & 26.00 \\
\hline 25.00 & 7.50 & 13.50 & 22.50 \\
\hline 30.00 & 4.90 & 8.50 & 14.00 \\
\hline 35.00 & 3.50 & 5.80 & 8.40 \\
\hline 40.00 & 2.50 & 4.20 & 6.00 \\
\hline 45.00 & 2.00 & 3.10 & 4.20 \\
\hline 50.00 & 1.50 & 2.50 & 3.10 \\
\hline 55.00 & 1.10 & 2.00 & 2.40 \\
\hline 60.00 & 0.80 & 1.50 & 2.00 \\
\hline 65.00 & 0.50 & 1.20 & 1.50 \\
\hline 70.00 & 0.25 & 0.90 & 1.10 \\
\hline
\end{tabular}

2. This table consist of numeric values of magnetic field from 14" LED monitors of three different products namely System A, System B and System C.
TABLE II: MAGNETIC FIELD FROM 14" LED MONITORS

\begin{tabular}{lccc}
\hline \hline DISTANCE & & & \\
FROM THE & SYSTEM & SYSTEM & SYSTEM \\
SCREEN & A & B & C \\
$($ CM) & $(50 / 60$ & $(50 / 60 H z:$ & $(50 / 60$ \\
& Hz: $1.4 A)$ & $1.4 A)$ & Hz: $1.4 A)$ \\
& (MILLI & (MILLI- & (MILLI \\
& -GAUSS) & GAUSS) & -GAUSS) \\
\hline \hline 5.00 & 13.00 & 18.00 & 20.00 \\
10.00 & 11.00 & 16.00 & 18.00 \\
15.00 & 8.30 & 13.50 & 13.30 \\
20.00 & 7.00 & 12.00 & 14.00 \\
25.00 & 5.00 & 10.00 & 12.00 \\
30.00 & 3.00 & 8.00 & 10.00 \\
35.00 & 2.20 & 7.20 & 9.50 \\
40.00 & 1.00 & 6.00 & 8.00 \\
45.00 & 0.80 & 5.80 & 7.80 \\
50.00 & 0.50 & 4.20 & 6.20 \\
55.00 & 1.20 & 3.30 & 5.30 \\
60.00 & 0.15 & 2.70 & 4.50 \\
65.00 & 0.10 & 2.00 & 4.00 \\
70.00 & 0.00 & 1.60 & 3.60 \\
\hline
\end{tabular}

3. This table consist of numeric values of magnetic field from 17" LCD monitors of three different products namely System A, System B and System C.

\begin{tabular}{|c|c|c|c|}
\hline \begin{tabular}{l}
\multicolumn{2}{l}{ DISTANCE } \\
FROM THE \\
SCREEN (CM)
\end{tabular} & $\begin{array}{l}\text { SYSTEM A } \\
(50 / 60 \mathrm{~Hz}: 1 . \\
\text { 5A) } \\
\text { (MILLI- } \\
\text { GAUSS) }\end{array}$ & $\begin{array}{l}\text { SYSTEM B } \\
(50 / 60 \mathrm{~Hz}: 1 . \\
5 \mathrm{~A}) \\
\text { (MILLI- } \\
\text { GAUSS) }\end{array}$ & $\begin{array}{l}\text { SYSTEM C } \\
(50 / 60 \mathrm{~Hz}: 1 . \\
5 \mathrm{~A}) \\
\quad \text { (MILLI- } \\
\text { GAUSS) }\end{array}$ \\
\hline 5.00 & 25.00 & 26.00 & 27.00 \\
\hline 10.00 & 22.00 & 24.00 & 25.00 \\
\hline 15.00 & 14.00 & 19.00 & 21.00 \\
\hline 20.00 & 8.50 & 10.00 & 12.50 \\
\hline 25.00 & 5.20 & 7.40 & 7.60 \\
\hline 30.00 & 3.70 & 4.80 & 4.80 \\
\hline 35.00 & 2.80 & 3.50 & 3.60 \\
\hline 40.00 & 2.00 & 2.75 & 2.60 \\
\hline 45.00 & 1.50 & 2.30 & 2.00 \\
\hline 50.00 & 1.10 & 1.60 & 1.40 \\
\hline 55.00 & 0.50 & 1.25 & 1.10 \\
\hline 60.00 & 0.30 & 1.00 & 0.80 \\
\hline 65.00 & 0.20 & 0.70 & 0.50 \\
\hline 70.00 & 0.10 & 0.20 & 0.20 \\
\hline
\end{tabular}

4. This table consist of numeric values of magnetic field 
from 17" LED monitors of three different products namely System A, System B and System C

\begin{tabular}{|c|c|c|c|}
\hline $\begin{array}{l}\text { DISTANCE } \\
\text { FROM THE } \\
\text { SCREEN } \\
\text { (CM) }\end{array}$ & $\begin{array}{l}\text { SYSTEM } \\
\text { A } \\
(50 / 60 \mathrm{~Hz}: \\
1.5 \mathrm{~A})(\mathrm{MILLI} \\
\text {-GAUSS })\end{array}$ & $\begin{array}{l}\text { SYSTEM B } \\
(50 / 60 \mathrm{~Hz}: \\
1.5 \mathrm{~A}) \\
\text { (MILLI- } \\
\text { GAUSS) }\end{array}$ & $\begin{array}{l}\text { SYSTEM C } \\
(50 / 60 \mathrm{~Hz}: 1.5 \\
\text { A) } \\
\text { (MILLI- } \\
\text { GAUSS) }\end{array}$ \\
\hline $\begin{array}{l}5.00 \\
\end{array}$ & $\begin{array}{lll}11.00 \\
\end{array}$ & $\begin{array}{lll}13.00 \\
\end{array}$ & $\begin{array}{ll}15.00 \\
\end{array}$ \\
\hline 10.00 & 9.00 & 11.00 & 13.00 \\
\hline 15.00 & 6.30 & 08.50 & 10.00 \\
\hline 20.00 & 5.00 & 07.00 & 09.00 \\
\hline 25.00 & 3.00 & 05.00 & 07.00 \\
\hline 30.00 & 1.00 & 03.00 & 05.00 \\
\hline 35.00 & 0.80 & 02.20 & 04.50 \\
\hline 40.00 & 0.50 & 01.00 & 03.00 \\
\hline 45.00 & 0.20 & 0.80 & 02.80 \\
\hline 50.00 & 0.15 & 0.50 & 0.40 \\
\hline 55.00 & 0.10 & 0.30 & 0.20 \\
\hline 60.00 & 0.00 & 0.10 & 0.10 \\
\hline 65.00 & 0.00 & 0.00 & 0.00 \\
\hline 70.00 & 0.00 & 0.00 & 0.00 \\
\hline
\end{tabular}

5. This table consist of numeric values of magnetic field from 21" LCD monitors of three different products namely System A, System B and System C.

\begin{tabular}{|c|c|c|c|}
\hline $\begin{array}{l}\text { DISTANCE } \\
\text { FROM THE } \\
\text { SCREEN } \\
(\mathrm{CM})\end{array}$ & $\begin{array}{l}\text { SYSTEM A } \\
\text { (50/60Hz: } 1 . \\
\text { 7A)(MILLI- } \\
\text { GAUSS) }\end{array}$ & $\begin{array}{l}\text { SYSTEM B } \\
(50 / 60 \mathrm{~Hz}: \\
1.7 A)(\mathrm{MILL} \\
\text { I-GAUSS) }\end{array}$ & $\begin{array}{l}\text { SYSTEMC } \\
\text { (50/60Hz:1.7 } \\
\text { A)(MILLI- } \\
\text { GAUSS) }\end{array}$ \\
\hline 5.00 & 22.00 & 23.00 & 25.00 \\
\hline 10.00 & 17.50 & 20.00 & 23.00 \\
\hline 15.00 & 11.00 & 12.00 & 20.00 \\
\hline
\end{tabular}

\begin{tabular}{llll}
20.00 & 7.20 & 06.50 & 13.00 \\
25.00 & 5.50 & 03.20 & 8.80 \\
30.00 & 3.30 & 01.70 & 6.20 \\
35.00 & 2.70 & 0.70 & 5.10 \\
40.00 & 1.90 & 0.40 & 3.30 \\
45.00 & 1.50 & 0.25 & 2.40 \\
50.00 & 1.12 & 0.10 & 2.00 \\
55.00 & 1.00 & 0.05 & 1.50 \\
60.00 & 0.60 & 0.01 & 1.20 \\
70.00 & 0.07 & 0.00 & \\
\hline 6.00 & & & \\
\hline
\end{tabular}

6. This table consist of numeric values of magnetic field from 21" LED monitors of three different products namely System A, System B and System C

\begin{tabular}{|c|c|c|c|}
\hline \begin{tabular}{l}
\multicolumn{2}{l}{ DISTANCE } \\
FROM THE \\
SCREEN (CM)
\end{tabular} & $\begin{array}{l}\text { SYSTEM } \\
\text { A } \\
\text { (50/60Hz: } 1 . \\
\text { 7A)(MILLI- } \\
\text { GAUSS) }\end{array}$ & \begin{tabular}{l}
\multicolumn{1}{c}{ SYSTEM } \\
B \\
$(50 / 60 \mathrm{~Hz}: 1.7 \mathrm{~A})$ \\
(MILLI- \\
GAUSS)
\end{tabular} & \begin{tabular}{l}
\multicolumn{1}{l}{ SYSTEM } \\
$\mathrm{C}$ \\
(50/60Hz:1.7A) \\
(MILLI- \\
GAUSS)
\end{tabular} \\
\hline 25.00 & 1.20 & 3.10 & 6.50 \\
\hline 10.00 & 0.80 & 2.30 & 3.80 \\
\hline 15.00 & 0.66 & 1.10 & 2.30 \\
\hline 20.00 & 0.45 & 0.80 & 1.80 \\
\hline 25.00 & 0.23 & 0.50 & 0.80 \\
\hline 30.00 & 0.17 & 0.40 & 0.30 \\
\hline 35.00 & 0.05 & 0.20 & 0.10 \\
\hline 40.00 & 0.00 & 0.10 & 0.00 \\
\hline 45.00 & 0.00 & 0.00 & 0.00 \\
\hline 50.00 & 0.00 & 0.00 & 0.00 \\
\hline 55.00 & 0.00 & 0.00 & 0.00 \\
\hline 60.00 & 0.00 & 0.00 & 0.00 \\
\hline 65.00 & 0.00 & 0.00 & 0.00 \\
\hline 70.00 & 0.00 & 0.00 & 0.00 \\
\hline
\end{tabular}


IV

\section{RESULTS AND DISCUSSION}

A. Results

A graph showing the magnetic field from 14" LCD and LED of System A type of monitor. The magnetic field in Milligauss is plotted against the Distance in $\mathrm{cm}$.

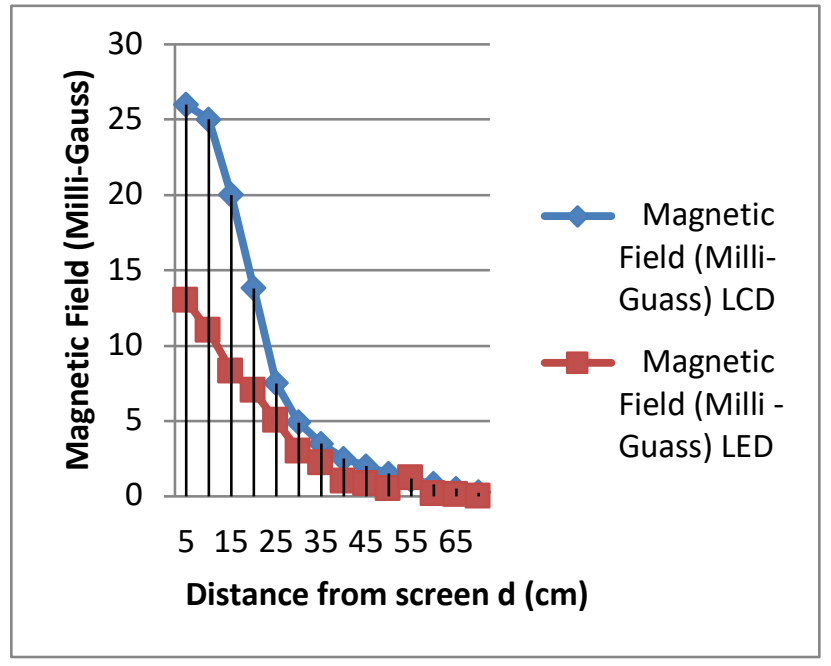

Fig. 4. Comparison of Magnetic Field from 14" LCD and LED of system A

A graph showing the magnetic field from 14" LCD and LED of System B type of monitor. The magnetic field in Milligauss is plotted against the Distance in $\mathrm{cm}$.

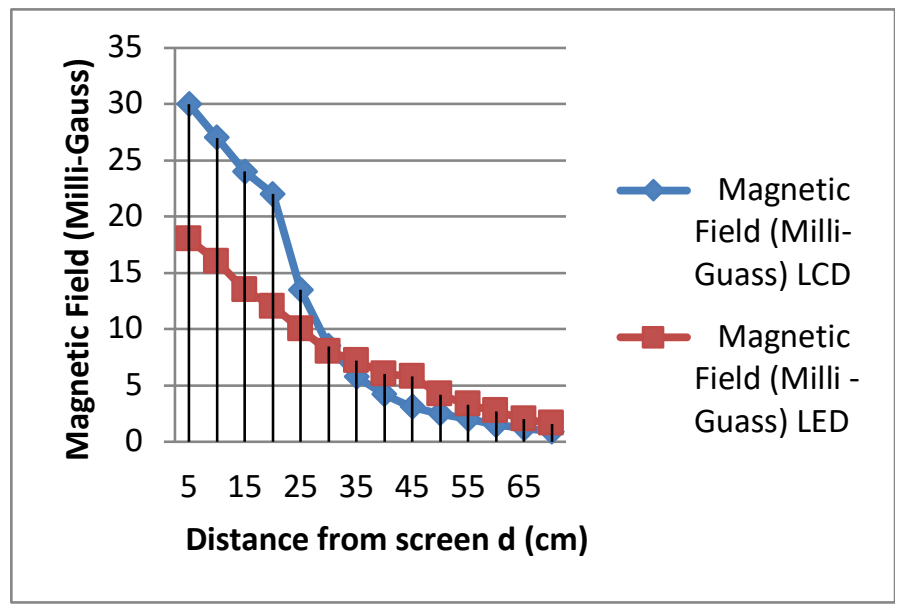

Fig. 5. Comparison of Magnetic Field from 14" LCD and LED of system

A graph showing the magnetic field from 14" LCD and LED of System C type of monitor. The magnetic field in Milligauss is plotted against the Distance in $\mathrm{cm}$.

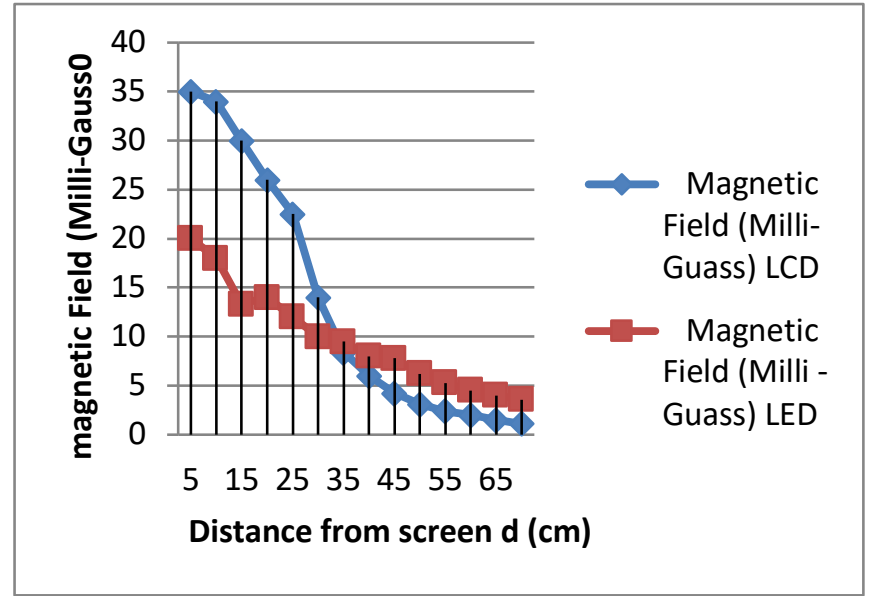

Fig. 6. Comparison of Magnetic Field from 14' LCD and LED of System $\mathrm{C}$

A graph showing the magnetic field from 14" LCD from System A, B and C. Magnetic field ( Milli Guass) is plotted against Distance $(\mathrm{cm})$

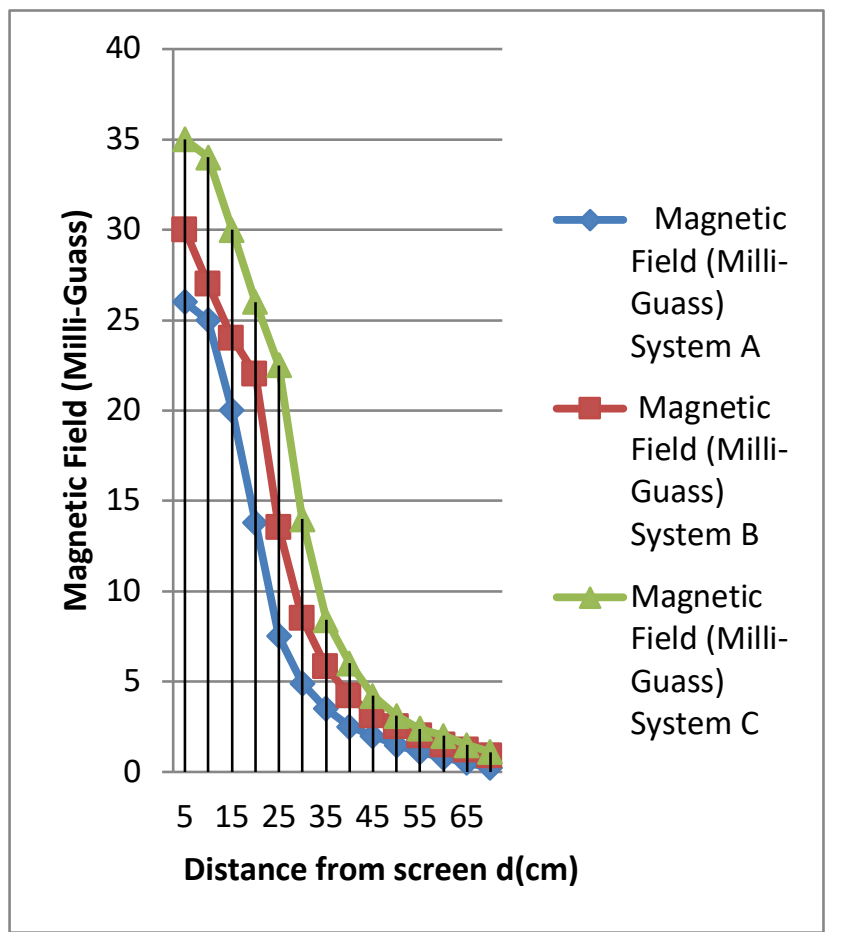

Fig. 7. Comparison of Magnetic Field from 14' LCD Systems

A graph showing the magnetic field from 14" LED from Systems A, B and C. Magnetic field (Milli Guass) is plotted against Distance(cm) 


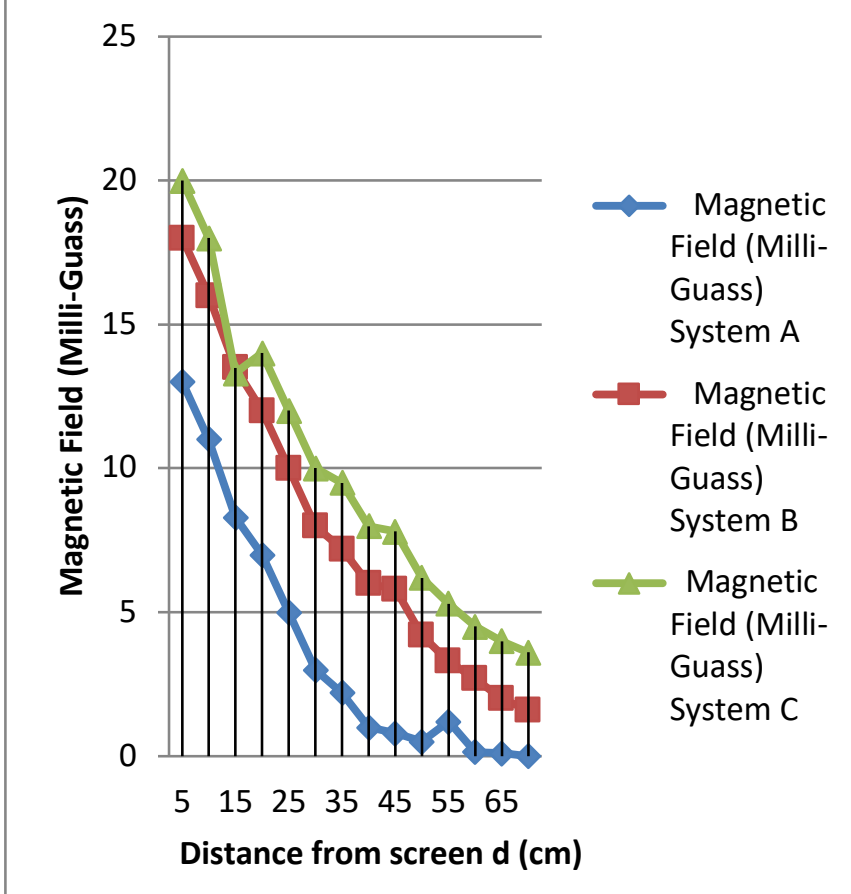

Fig. 8. Comparison of Magnetic Field from 14' LED Systems

A graph showing the magnetic field from 17" LCD from Systems A, B and C. Magnetic field (Milli Guass) is plotted against Distance $(\mathrm{cm})$

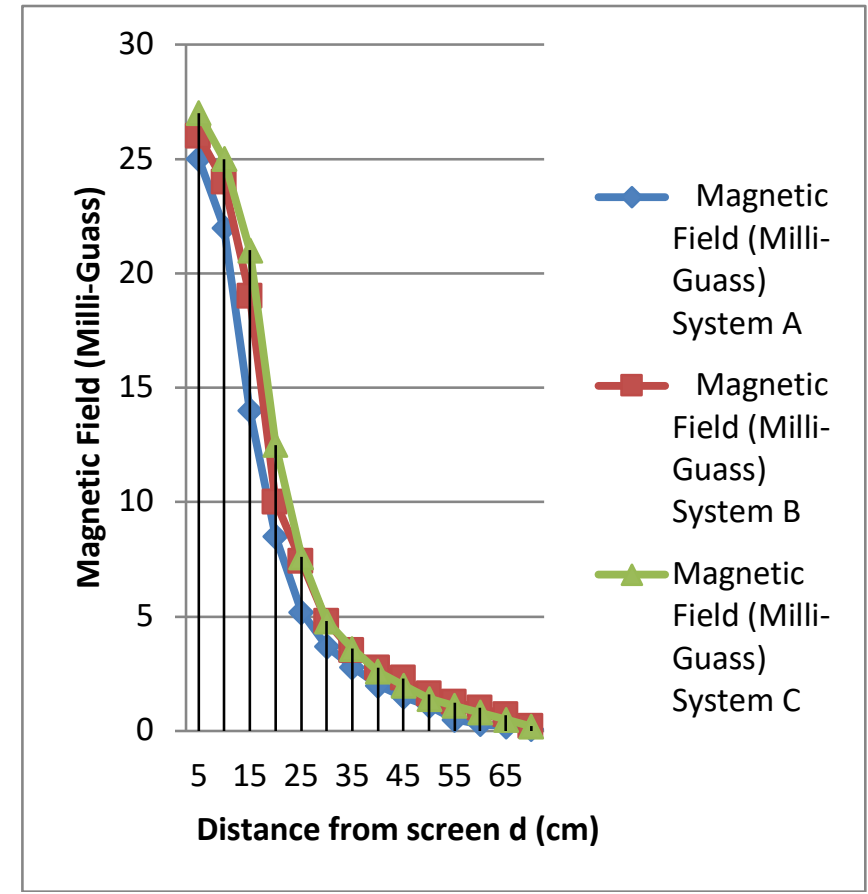

Fig. 9. Comparison of Magnetic Field from 17" LCD Systems

A graph showing the magnetic field from 17" LED from Systems A, B and C. Magnetic field ( Milli Guass) is plotted against Distance $(\mathrm{cm})$

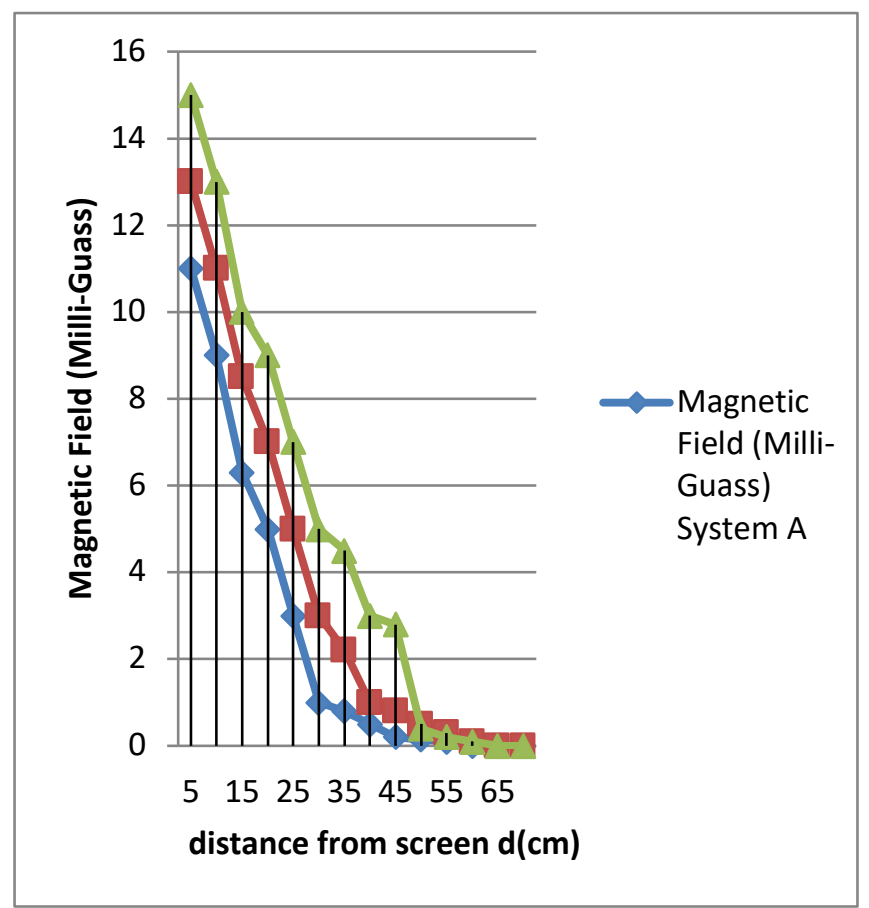

Fig. 10. Comparison of Magnetic Field from 17" LED Systems

A graph showing the magnetic field from 21" LCD from Systems A, B and C. Magnetic field (Milli Guass) is plotted against Distance $(\mathrm{cm})$

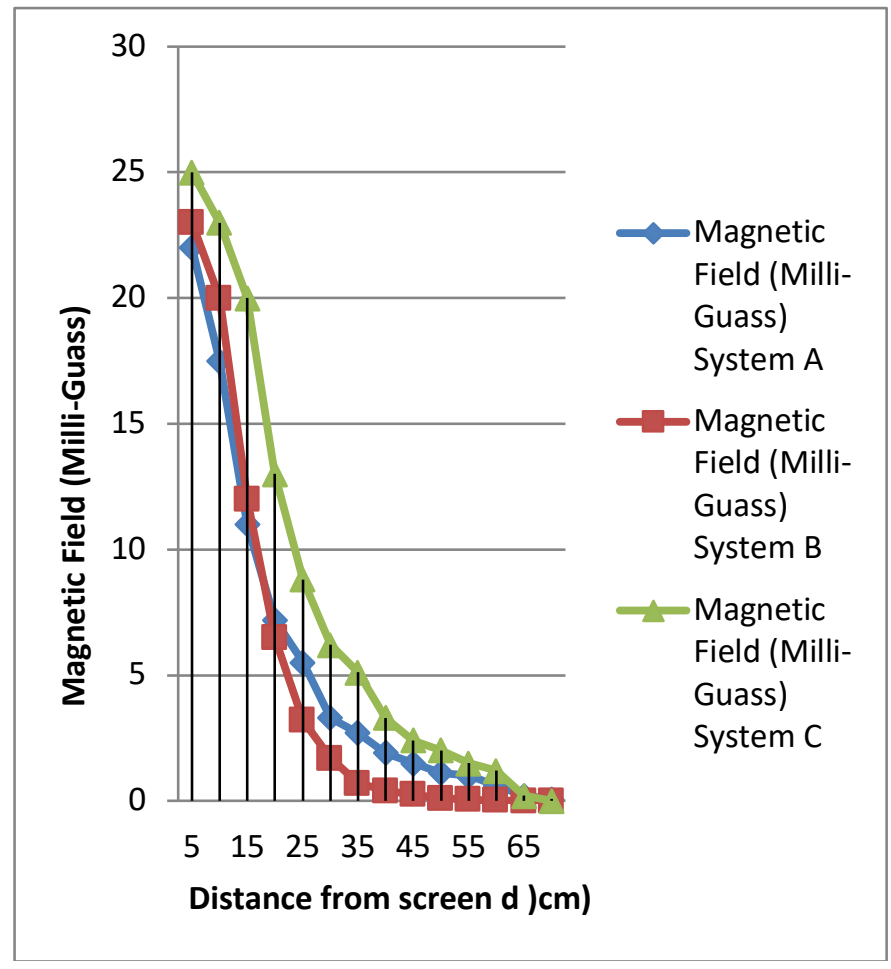

Fig. 11. Comparison of Magnetic Field from 21" LCD Systems

A graph showing the magnetic field from 21 " LED from Systems A, B and C. Magnetic field ( Milli Guass) is plotted against Distance $(\mathrm{cm})$ 


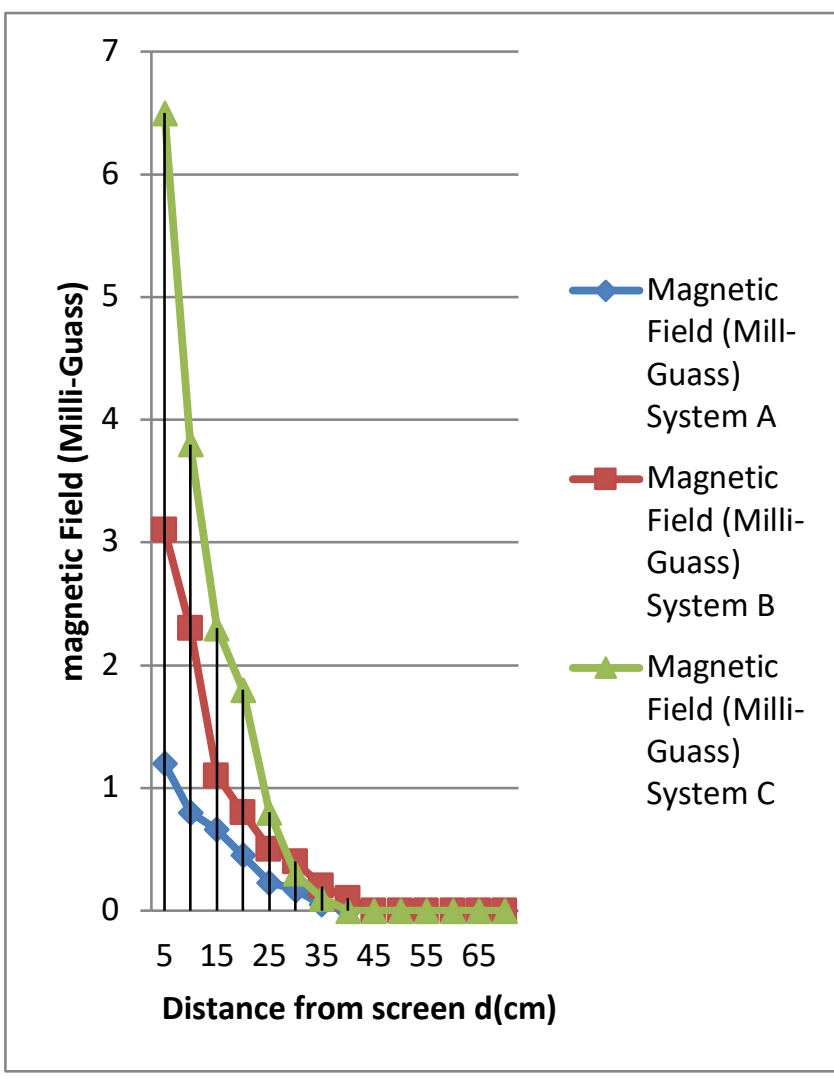

Fig. 12. Comparison of Magnetic Field from 21" LED Systems

\section{B. Discussions}

This study has shown that LCD and LED computer monitors emit magnetic field. A total of 18 LCD and LED computermonitors of different products were investigated using the Tri Field Gauss metre. The results have shown that induced magnetic field of liquid crystal display monitors are greater than the Light emitting diode. In general, the measured magnetic field results obtained are very low and below the recommended limits established for the protection by the non-ionizing radiations emitted by video display units (VDU). Thus, there is no evidence from this study that the use of LCD computer monitors could be traced to adverse health effect like spontaneous abortion, cancer etc. Meanwhile, caution should be applied especially for prolonged exposure.

The results obtained in this work have confirmed the presence of induced magnetic field on Liquid Crystal Display (LCD) and Light Emitting Diode (LED) computer monitor. The obtained result show the magnetic field induction of the LCD monitor is almost 2 times greater than that Of the LED monitors.

Secondly, it was found that there is dependence of computer monitors magnetic field induction on the distance from the screen. In this study, measurements were performed every $5 \mathrm{~cm}$ up to $70 \mathrm{~cm}$ distance by placing the trifield gauss meter in front of the screen at varying distances. The obtained result show that the increase in the distance from the monitor screen the magnetic field induction rapidly decreases. The analysis shows that the magnetic field induction at $65 \mathrm{~cm}$ from the screen for LCD computer monitor has become insignificant and almost negligible while that of magnetic field induction at $40 \mathrm{~cm}$ for the LED monitors was already insignificant.
Thirdly, the magnetic field strength emanating from different units vary with product design. Also, there is a slight decrease of magnetic field induction from computer monitors with increase in size of the screen. Thus, monitors of 14 inches are likely to produce more magnetic field induction than 21 inches counterpart.

Also the range of field produce by LCD and LED monitors were found to be below international standard maximum permissible dose.

\section{CONCLUSION}

This work has confirmed the presence of induced magnetic field on computer monitors screens. A reliable technique was used to measure the field distribution at varying distances from the screen. A total of 18 monitors of different sizes, both LCD and LED from different manufacturers were investigated. The experiments have shown that magnetic field induction of the LCD Monitors is almost 2 times greater than that of the LED monitors. The levels of induced magnetic field obtained in this study are below the limit of permissible dose according to the IEEE standard.

\section{REFERENCES}

[1] Agba, and Ayangeakaa, , Radiation Levels from Computer Monitors Screen within Benue State University, Makurdi. Nigerian Journal of Physics, 17, 46-49.(2015)

[2] B.I. Bakare, F.M. Nwakpang and A.E.Desire. Propagation and Analysis of Radio Frequency (RF) Signal of Love FM Transmitter in Port Harcourt, Nigeria, IOSR Journal of Electronics and Communication Engineering Vol.14, Iss.2 pp 05-12, Apr.2019.

[3] Gediminas, Investigation of Magnetic Fields LCD Monitors Using a Personal Computer. International IEEE Committee on man and radiation (COMAR) 1997:

[4] B.I. Bakare and J.C Ozogbuda. Measurement and Analysis of Electromagnetic Field Strength in Port Harcourt and its Environs Due to Treasure F.M Radio Transmitter, European Journal of Electrical and Computer Engineering .2(4).pp.09-14. May 2018.

[5] Laogun, (1997), A comparison of Dielectric behavior of Human Haemoglobn SC, with SS, and AA in solution.Journal of physics, Med. Biol, 42, 707-713

[6] Laogun, (2009). Lecture note on solid state physics. Unpublished

[7] Nte and Michael (2013) Measurement of magnetic fields from liquid crystal display (LCD) 'computer monitors. International Journal of Current Research

[8] Bellieni, Pinto, Bogi, Zoppetti, Andreuccetti, Buonocore (2012). Exposure to Electromagnetic Fields From Laptop Use of "Laptop" Computers

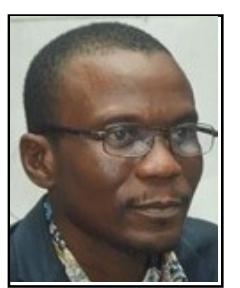

B. I. Bakare holds a Bachelor of Engineering (B.Eng.) Degree in Electrical Engineering; $2^{1}$ from Ondo State University, Ado Ekiti, ( Now University of Ado Ekiti, Ekiti State), Master of Engineering (M.Eng.) Degree in Electrical/Electronic Engineering from University of Port Harcourt, Nigeria and he is currently a $\mathrm{PhD}$ (Communication Engineering) Researcher of Nnamdi Azikiwe University (Unizik), Awka, Anambra State. He holds a Category One Electrical Wiring License. He is a COREN registered Engineer, a Corporate Member of Nigeria Society of Engineers (NSE), a member of International Association of Engineers (I A ENG) and an active member of Nigeria Institute of Electrical and Electronics Engineers (NIEEE). He is presently a lecturer in the Department of Electrical Engineering, Rivers State University, Port Harcourt., Nigeria. He is married with children. 


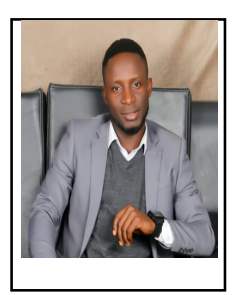

Victor T. Taol holds a Bachelor degree of Science (B. Sci.) degree in Electronics Physics from Niger Delta University, Bayelsa State, Post graduate diploma (PGD) degree in Electrical Engineering from Federal University of Technology Owerri, Imo State, and he is currently an M. Tech

(communication Engineering option) Researcher of the Rivers State University, Nkpolu Oruworukwo,

Rivers State.

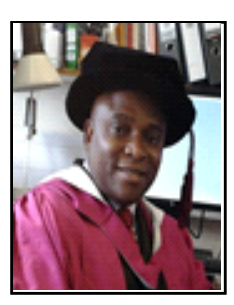

Sunny Orike received his B. Tech. in Computer Engineering from Rivers State University of Science and Technology (now Rivers State University); M.Sc. in Computing and M.Phil. in Computational Intelligence, both from Robert Gordon University, Aberdeen, United Kingdom; and Ph.D in Artificial Intelligence from Heriot-Watt University, Edinburgh, United Kingdom.

Dr. Orike is an active member of several professional bodies, including Council for the Regulation of Engineering in Nigeria, Nigeria Institution of Electrical Electronic Engineers and International Association of Engineers. He is a Senior Lecturer and Presently the Head, Computer Engineering Department, Rivers State University, Port Harcourt, Nigeria. 